\title{
O PROFESSOR DE LEITURA EM LÍNGUA ESTRANGEIRA E A APRENDIZAGEM COLABORATIVA
}

\author{
BARBRA SABOTA*
}

\begin{abstract}
RESUMO
O presente artigo apresenta algumas reflexões sobre o papel do professor durante a aula de leitura em língua estrangeira juntamente ao desenvolvimento do trabalho colaborativo. Utilizamos, a fim de atingir tal propósito, alguns dados coletados em nossa pesquisa de mestrado. Buscamos despertar o debate sobre a importância da atitude consciente do professor na aula de leitura em língua estrangeira.
\end{abstract}

Palavras-CHave: aprendizagem colaborativa, professor de língua estrangeira.

The foreign language reading teacher and the collaborative learning

\section{Abstract}

This article presents some assumptions about the role of the collaborative teacher during reading comprehension exercises in an EFL classroom. The data discussed here come from the dissertation we wrote and defended in 2002. The aim of this study is, then, to foster debate about the importance of a conscious attitude on behalf of the teacher in the EF L reading lesson.

KEY worDs: collaborative learning, foreign language teacher.

\section{INTRODUÇÃo}

O professor que ministra uma aula de leitura em uma língua estrangeira (LE) desempenha um papel muito importante na formação do leitor. Freire (2000) já nos dizia que ensinar é muito mais do que "transferir conhecimento". É preciso muita disciplina para não influenciar os alunos durante o processo da leitura, já que o professor de leitura deve se portar como um "gerenciador da aprendizagem" (Williams, 1986). Para tanto, ao organizar o "cenário" em que a aprendizagem ocorre, o professor deve fornecer condições para que a

* Professora adjunto da Universidade Paulista (Unip) e professora efetiva de Prática de Ensino de Língua Inglesa da Universidade Estadual de Goiás (UEG). Mestre em letras e lingüística pela UFG e doutoranda na mesma instituição. E-mails: bsabota@ig.com.brou barbrasabota@brturbo.com.br 


\section{Revista Solta a Voz, v. 16, n. 1}

interlocução seja estabelecida (Kleiman, 2001), bem como favorecer a construção do conhecimento (Freire, 2000) durante a interação com o texto. Em outras palavras, cabe ao professor proporcionar oportunidades em suas aulas para que os alunos expressem suas idéias e opiniões a respeito do texto, deixando de exigir que eles repitam a ideologia do estado e/ou do professor (Coracini, 1995; Orlandi, 1999a, 1999b). Murce Filho (1998) observou, em seu estudo, que o deslocamento da posição clássica e centralizadora do professor para a posição de ouvinte reserva aos alunos uma postura mais ativa na análise dos textos, despertando neles a vontade de recriar e atribuir novos significados ao que lêem.

Encontramos, na literatura especializada, algumas características do que é considerado um bom professor de leitura (Richards, 1990; Nunan, 1991; Moita Lopes, 1996; Nuttall, 1996; Aebersold e Field, 1997; Kleiman, 2001; Terzi, 2001). O bom professor de leitura é aquele que:

- proporciona o ambiente necessário para que o aluno crie condições de recuperar sua condição de sujeito avaliador da própria leitura;

- vê na realização das tarefas a serem executadas em sala de aula uma oportunidade de aprendizagem e não de teste;

- não sobrepõe sua opinião a dos outros;

- preocupa-se com a construção de esquemas. Na teoria sobre leitura, o termo esquema refere-se ao conhecimento prévio construído ao longo da vida por meio das diversas experiências vivenciadas. Assim, o professor analisa que conhecimento esquemático seria necessário ao entendimento do texto, e supre eventuais faltas utilizando exercícios de pré-leitura ou dicas durante a leitura;

- permite que dúvidas sejam tratadas em conjunto;

- abre espaço para debate, permitindo que os alunos expressem seus pontos de vista;

- usa exercícios variados durante uma mesma aula para abranger diferentes estilos de aprendizagem e as outras habilidades da língua: escrita, compreensão oral e produção oral;

- conhece as capacidades e limitações de seus alunos e elabora exercícios para serem realizados em sala de aula que se assemelhem às discussões e tarefas encontradas na vida real; 
- tem conhecimento aprofundado sobre leitura, especialmente sobre leitura em LE, e tudo o que ela abrange. Logo, toma decisões adequadas, baseadas em fontes empíricas e teóricas;

- escolhe textos atraentes, para as discussões em sala, que sejam condizentes com as expectativas dos alunos e que estejam bem adequados ao conteúdo proposto pelo programa.

Além dessas características citadas sobre o bom professor de leitura, Gillette (1994), Dalacorte (2000) e Lied (2002) citam o comportamento aberto e amistoso do professor de línguas como um fator favorável à manutenção da motivação dos alunos para participar em sala de aula.

Vimos, então, que o bom professor de leitura é aquele que conhece as potencialidades e limitações de seus alunos, levando-as em consideração ao planejar suas aulas. Observamos, ainda, que, assim como qualquer outro professor interessado em gerar interação entre seus alunos, o bom professor de leitura proporciona um ambiente tranqüilo para que a aprendizagem se desenvolva.

Dentro dessa perspectiva, entendemos que o trabalho do professor de leitura está muito próximo ao papel do professor previsto pela teoria sociocultural. Cabe ressaltar, ainda, que não ambicionamos traçar um modelo ideal a ser seguido, mas sim discutir algumas das principais características apresentadas por essa teoria, a fim de motivar um novo posicionamento profissional perante os alunos e a resolução de exercícios de compreensão textual. Apresentamos, a seguir, algumas das principais atribuições desse educador.

\section{UM NOVO CENÁRIO: O TRABALHO COLABORATIVO E O NOVO PAPEL DO PROFESSOR}

O trabalho colaborativo tem sido utilizado em várias áreas do processo de ensino-aprendizagem de línguas. A aprendizagem colaborativa é um termo empregado para se referir ao tipo de aprendizagem decorrente do uso de atividades em grupo para a realização de tarefas pelos alunos (Bruffee, 1999).

Ohta (2001, p. 76) cita, como um benefício da atividade colaborativa, o fato de "os alunos criarem sua própria atividade de aprendizagem de língua", pois eles têm um tema a ser discutido, mas 


\section{Revista Solta a Voz, v. 16, n. 1}

quem dirige o rumo das negociações e quem decide o que deverá ser utilizado e aprendido são os próprios alunos. Assim, durante o desenvolvimento de atividades colaborativas, os alunos se envolvem ativamente em um processo de construção de significado e negociações sobre como proceder durante a realização das tarefas propostas. Os alunos, então, aprendem a ser mais autônomos e responsáveis como mostram as pesquisas de Figueiredo (2001), Sabota (2002), entre outros.

A utilização dessas atividades redimensiona a dinâmica da aula de língua, uma vez que o foco sai do professor e se volta não só para os alunos, mas também para os trabalhos por eles realizados. O professor de línguas tem a sua frente, então, um novo desafio. Vale dizer, uma vez que, durante o trabalho em grupo, o professor já não ocupa o centro da interação, ele passa a ter mais tempo para dar assistência personalizada aos alunos durante a realização das tarefas estabelecidas. Assim, surgem novos papéis para o professor:

a) o de monitor da aprendizagem (Kohn e Vajda, 1975), que verifica o progresso dos pares/grupos durante a atividade e os auxilia a redirecionar a atenção;

b) o de consultor (Nuttall, 1996; Voller, 1997), no caso de dúvidas que persistem mesmo depois da ajuda do colega ou que surgem em decorrência da interação entre os aprendizes;

c) o de conciliador (Richards, 1990; Nuttall, 1996), caso haja algum atrito entre os integrantes do grupo;

d) o de promotor de oportunidades para mudanças em parceria com o aprendiz em prol de seu desenvolvimento (Paiva e Freitas, 1994);

e) o de facilitador (Olsen e Kagan, 1992), ou seja, o promotor de um ambiente favorável à aprendizagem em grupos mediando o processo e não o controlando. Segundo Underhill (1999), o professor que ocupa o papel de facilitador, além de apresentar conhecimento sobre o tópico que pretende ensinar e familiaridade com os métodos e procedimentos de ensino, estuda atentamente a "atmosfera psicológica" em que a aprendizagem ocorre, avaliando o progresso dos alunos "com o objetivo de capacitar os alunos a assumir a responsabilidade por sua aprendizagem" (Underhill, 1999, p. 126); e, finalmente;

f) o de co-aprendiz (Wells, 1997; Richards, 2002), pois, na aprendizagem colaborativa, a troca de experiências de vida entre alunos e professor conta tanto quanto o aspecto lingüístico da aula de LE. 
Dessa forma, unindo essas características às já descritas na primeira parte deste artigo, podemos perceber que, durante as aulas de leitura, o professor deve se manter atento para não deixar que sua resposta direcione a resposta dos alunos. Durante o trabalho em pares/grupos, o professor deve estar presente para consultas. Porém, isso não significa que ele deva resolver os problemas pelos alunos (Nuttall, 1996). É importante ainda que o professor de leitura em língua estrangeira, ao promover a atividade colaborativa, se disponha a discutir com os grupos o sentido do texto, permitindo que os alunos participem ativamente do processo de compreensão textual.

Em um estudo sobre a resolução colaborativa de exercícios de compreensão textual (Sabota, 2002), delineamos vários aspectos positivos sobre a utilização de atividades colaborativas durante o desenvolvimento da habilidade de leitura, dentre eles: maior interação entre os alunos; aprendizagem conjunta de vocabulário e de estratégias de leitura; maior motivação para ler e maior segurança ao elaborar respostas e ao emitir opiniões; aumento da auto-estima; os alunos tomam uma posição mais ativa na aprendizagem; produção autêntica de língua, proporcionando oportunidades de prática oral.

Foi possível perceber ainda algumas mudanças de atitude, como o fato de eles se mostrarem mais responsáveis, mais assíduos, mais interessados pela aprendizagem, e, ainda, mais autônomos, tomando suas próprias decisões e gerenciando sua aprendizagem. Entretanto, esses benefícios não poderiam ter sido percebidos caso o professor não se conscientizasse da importância do seu papel dentro dessa perspectiva de trabalho, ou seja, foi necessário que o professor ocupasse seu papel de monitor, facilitador e promotor de oportunidades de mudança de atitudes conforme vimos anteriormente.

Na seqüência, apresentamos alguns exemplos nos quais podemos perceber a demonstração de algumas dessas características.

\section{NOVAS VOZES - ANÁLISE DOS DADOS}

Em nossa dissertação de mestrado (Sabota, 2002) investigamos as estratégias utilizadas durante a resolução colaborativa de exercícios de compreensão textual por oito alunos do terceiro ano de Letras da UFG. Durante três aulas eles interagiram em pares durante a leitura, e um dos recursos escolhidos foi o auxílio de fontes externas - ou seja, a 


\section{Revista Solta a Voz, v. 16, n. 1}

consulta a elementos não pertencentes ao texto para completar a compreensão do texto. Nossos alunos recorreram a duas fontes externas: o dicionário e o professor. $\mathrm{O}$ uso de dicionário serviu para resolver dúvidas dos pares quanto ao significado das palavras e à pronúncia. $\mathrm{O}$ professor, por sua vez, foi consultado, basicamente, para resolver impasses gerados pelos alunos durante a atividade.

Vejamos um trecho da interação do professor e alguns alunos do estudo (Sabota, 2002), a fim de ilustrar o posicionamento do professor diante da atividade. Neste trecho, as alunas Edith e Bia (pseudônimo adotado pelas alunas) negociam a resolução de um exercício de compreensão textual referente a um texto lido por elas para a aula em questão. A negociação das alunas gera um impasse e elas não se sentem seguras para decidir. Refletindo uma postura tradicional de situação de ensino, as alunas buscam o auxílio do professor, Leonardo, para validar o ponto de vista de uma delas, dando fim ao impasse. O professor, por sua vez, as auxilia sem lhes dar a resposta diretamente, incentivando-as a tirar suas próprias conclusões, executando, assim, seu papel de facilitador e monitor da aprendizagem. As alunas, diante da atitude do professor, utilizam outros recursos, como a argumentação baseada em trechos do texto para resolver o problema em questão:

[1] Edith: Leonardo, I think this letter ' $C$ ' is top model, she thinks is secretary

$\rightarrow$ Professor: Hum?

Edith: : So?

$\rightarrow$ Professor: Wha-why do you think this person is a top model? Try to convince her or vice-versa, if you think this person is a secretary, try to convince her. Ok?

Edith: Hum...

Bia: $\quad$ I said to her... Twice!

$\rightarrow$ Professor: Why? Why do you think this person is a secretary?

Edith: $\quad$ She told me but...

$\rightarrow$ Professor: ... you don't agree...

Edith: No, I agree, but I think my response is correct... my re-my answer is correct

$\rightarrow$ Professor: You answer is correct? 
Edith: I think. (risos)

$\rightarrow$ Professor: Ok, so you keep your answer... right?

Bia: $\quad$ Tell me why you think is a top model.

Edith: Because she... she is preoccupied with how she...she wear... yes? And... and she... and the person said: "I never lost my embarrassment at meeting people whose prime interest was in my physical appearance."

Bia: Hum..

(Edith e Bia - interação sobre o texto Sports)

Os alunos envolvidos na pesquisa aprovaram não só a nova forma de trabalhar a leitura, mas o novo posicionamento do professor, pois eles conseguiram perceber o quanto aprenderam colaborativamente. $\mathrm{O}$ trecho a seguir, retirado da entrevista com os alunos, ilustra tal posicionamento:

[2] Barbra: Você acha que esta atividade interferiu de alguma forma na sua visão de leitura em língua estrangeira?

Nicole: Acaba influenciando porque a gente acaba se desenvolvendo mais.. É bom quando o professor desenvolve o texto com a gente em sala... quando você trabalha, o professor e aluno e tal, mas quando você... a relação é diferente: professorprofessor, aluno-aluno. Assim... como a gente está no mesmo patamar, no mesmo nível... né, é diferente... Então, isso acaba ajudando a gente a desenvolver a leitura no inglês, na área de língua estrangeira.... não que o professor coloque barreira, mas a gente mesmo, o próprio aluno coloca essa barreira, porque a gente se sente tímido pra falar com o professor, medo de errar, não com o nosso professor, que a gente tem, assim, ... a maior afinidade.. muita afinidade mesmo.. mas a relação professor-aluno, ela é assim, o aluno acaba colocando uma barreira. E pra desenvolver essa atividade com o colega... isso acaba 
18 Revista Solta a Voz, v. 16, n. 1

gerando maior confiança e você acaba transmitindo isso na sua oralidade pro professor ... então ajudou muito!

(Nicole - entrevista)

Os resultados do estudo permitem inferir que os alunos, na medida em que se tornam mais independentes do professor, passam a aumentar sua auto-estima em relação ao que conseguem realizar em sala de aula. O professor, diante de alunos mais independentes, passa a ter mais condições de se dedicar aos que mais precisam de seu auxílio em classe e ao mesmo tempo os auxilia a conseguir melhores resultados a partir das atividades desenvolvidas na aula de LE. Contudo, o posicionamento do professor reflete sua formação e suas crenças. Assim, o professor Leonardo, participante deste estudo, só pôde auxiliar seus alunos a interagir colaborativamente porque fazia parte de sua formação profissional o questionamento sobre como auxiliar seus alunos a serem mais independentes. O exemplo 3 ilustra como o professor se interessou pelo uso de atividades colaborativas em sala de LE:

[3] Barbra: Há quanto tempo você vem utilizando o trabalho colaborativo em suas aulas?

Professor: Ah, eu sempre usei atividades em grupos, em pares, mas não com tanta freqüência, né, eu tenho usado mais esse tipo de trabalho após o meu doutorado, porque minha pesquisa foi sobre aprendizagem colaborativa, relacionada à correção, então eu pude ver os benefícios desse tipo de abordagem para o ensino e, aí, atualmente, eu tenho feito bastante esse tipo de trabalho.

(Leonardo - entrevista)

Como se vê, pelo exemplo acima, o contínuo estudo, por parte do professor, é necessário para que o profissional se mantenha sempre atualizado em relação ao que ele pode fazer para melhorar os resultados de seu trabalho, pois, conforme é possível perceber através dos estudos e dos exemplos citados neste artigo, a aprendizagem colaborativa traz vários benefícios para os alunos. 
Revista Solta a Voz, v. 16, n. 119

\section{Novos DESAFIOS: CONSIDERAÇÕES FINAIS}

Por meio do trabalho colaborativo, os alunos interagentes puderam compartilhar estratégias de leitura e esquemas, praticar a línguaalvo, além de conhecerem melhor seus próprios colegas. Entretanto, conforme sustentamos ao longo do texto, isso só foi possível diante da postura inovadora adotada pelo professor ao conduzir sua aula.

O professor tem o poder de controlar a aula ou conduzi-la. A nosso ver, o professor, dentro da aprendizagem colaborativa, direciona a aula e as discussões, auxilia os alunos não só a se sentirem mais capazes e seguros - reforçando sua auto-estima - , mas também a trabalharem em conjunto, ouvindo e respeitando a opinião do outro em um processo de co-aprendizagem. Faz-se necessário, pois, que o professor se prepare bem para assumir esta nova postura, uma vez que toda mudança de atitude envolve reflexão e maturação de idéias.

Dessa forma, acreditamos que mais pesquisas deveriam ser feitas nesta área, uma vez que nossos estudos, ainda que incipientes, nos permitem concluir que uma nova postura do professor de leitura do século XXI será bem diferente daquela exercida por professores de outros tempos. Cabe a cada um de nós, professores e pesquisadores em lingüística aplicada, o papel de auxiliar a montar o novo cenário que se forma e incentivar a discussão sobre a utilização da aprendizagem colaborativa em sala de LE e sobre a formação do professor.

\section{REFERÊNCIAS}

AEBERSOLD, J. A.; FIELD, M. L. from reader to reading teacher. Cambridge: Cambridge University Press, 1997.

BRUFFEE, K. A. Collaborative learning. London: The Johns Hopkins University Press, 1999.

CORACINI, M. J. F. Leitura: decodificação, processo discursivo...? In: CORACINI, M. J. F. (Org.). O jogo discursivo na aula de leitura. Campinas, SP: Pontes, 1995. p. 13-20.

DALACORTE, M. C. F. A participação dos aprendizes na interação em sala de aula. In: DALACORTE, M. C. F.; MELLO, H. A. B. (Org.). A sala de aula de lingua estrangeira. Goiânia: Editora da UFG, 2000. p. 39-62. 


\section{Revista Solta a Voz, v. 16, n. 1}

FIGUEIREDO, F. J. Q. de. Correção com os pares: os efeitos do processo da correção dialogada na aprendizagem da escrita em língua inglesa. Belo Horizonte, 2001. Tese (Doutorado em Letras: Estudos Lingüísticos) - Faculdade de Letras, Universidade Federal de Minas Gerais, Belo Horizonte, 2001.

FREIRE, P. Pedagogia da autonomia: saberes necessários à prática educativa. 15. ed. São Paulo, SP: Editora Paz e Terra, 2000.

GILLETTE, B. The role of learner goals in 12 success. In: LANTOLF, J. P.; APPEL, G. (Ed.). Vygotskian approaches to second language learning. Norwood, N. J.: Ablex Publishing Company, 1994. p. 195-213.

KLEIMAN, A. Leitura: ensino e pesquisa. 2. ed. Campinas: Pontes, 2001.

LIED, J. I. F. Reflections on teaching english and students' motivation. Lajeado, RS: Gráfica e Editora Pallotti, 2002.

MOITA LOPES, L. P. Um modelo interacional de leitura. In: MOITA LOPES, L. P. (Org.). Oficina de lingüística aplicada. Campinas, SP: Mercado das Letras, 1996. p. 137-146.

MURCE FILHO, N. F. Aulas "alternativas" de leitura em lingua estrangeira: histórias "provocadoras" e deslocamentos de posições subjetivas. 1998. Dissertação (Mestrado em Lingüística Aplicada) - Instituto de Estudos da Linguagem, Unicamp, Campinas, SP, 1998.

NUNAN, D. Language teaching methodology: a textbook for teachers. New York, NY: Prentice Hall, 1991.

NUTTALL, C. Teaching reading skills in a foreign language. Hong Kong: Macmillan Heinemann ELT, 1996.

OHTA, A. S. Rethinking interaction in SLA: developmentally appropriate assistance in the zone of proximal development and the acquisition of L2 grammar. In: LANTOLF, J. P. (Ed.). Sociocultural theory and second language learning. Hong Kong: Oxford University Press, 2001. p. 51-78.

OLSEN, R. E. W-B.; KAGAN, S. About cooperative learning. In: KESSLER, C. (Ed.). Cooperative language learning: a teacher's resource book. New Jersey: Prentice Hall Regents, 1992. p. 1-30.

ORLANDI, E. P. Discurso e leitura. 4. ed. Campinas, SP: Cortez, 1999a. 
Revista Solta a Voz, v. 16, n. 121

. A produção de leitura e suas condições. In: BARZOTTO, V. H. (Org.). Estado de leitura. Campinas, SP: Mercado das Letras, 1999b. p. 47-60.

PAIVA, M. G. G; FREITAS, S. W. D. Vygotsky, second language acquisition and learner autonomy: some preliminary considerations. In: LEFFA, V. J. (Ed.). Autonomy in language learning. Porto Alegre, RS: Editora da Universidade/UFGRS, 1994. p. 36-44.

RICHARDS, J. C. A profile of an effective reading teacher. In: RICHARDS, J. C. (Ed.). The language teaching matrix. Cambridge: Cambridge University Press, 1990. p. 87-99.

. Theories of teaching in language teaching. In: RICHARDS, J. C; RENANDYA, W. A. (Ed.). Methodology in language teaching: an anthology of current practice. Cambridge: Cambridge University Press, 2002. p. 19-25.

SABOTA, B.R.S. Leitura em lingua inglesa: a resolução colaborativa de exercícios de compreensão textual. 2002. Dissertação (Mestrado em Letras e Lingüística) - Faculdade de Letras, UFG, Goiânia, 2002.

TERZI, S. B. A construção da leitura. 2. ed. Campinas, SP: Pontes, 2001.

UNDERHILL, A. Facilitation in language teaching. In: ARNOLD, J. (Ed.). Affect in language learning. Melbourne: Cambridge University Press, 1999. p. 125-141.

VOLLER, P. Does the teacher have a role in autonomous language learning? In: BENSON, P.; VOLLER, P. (Ed.). Autonomy and independence in language learning. New York: Addison Wesley Longman, 1997. p. 99-113.

WELLS, G. The zone of proximal development and its implications for learning and teaching, 1997. Disponível em: $<\underline{\text { http:/ / www.oise.utoronto.ca/ }}$ $\sim$ gwells/zpd.discussion.txt>. Acesso em: 24 set. 1998.

WILLIAMS, R. 'Top ten' principles for teaching reading. ELT Journal, v. 40, n. 1, p. 42-45, 1986.

KOHN, J. J.; VAJDA, P. G. Peer mediated instruction and small group interaction in the ESL classroom. Tesol Quarterly, v. 9, n. 4, p. 379-390, 1975.

Recebido em: 18 jan. 2005

Aceito em: 12 abr. 2005 